\title{
Inhibition of growth and migration of cholangiocarcinoma cells by pamidronate
}

\author{
BENJAPORN BURANRAT ${ }^{1}$, AUEMDUAN PRAWAN ${ }^{2,3}$, LADDAWAN SENGGUNPRAI ${ }^{2,3}$ \\ and VEERAPOL KUKONGVIRIYAPAN ${ }^{2,3}$
}

\author{
${ }^{1}$ Faculty of Medicine, Mahasarakham University, Muang, MahaSarakham 44000; ${ }^{2}$ Department of Pharmacology, \\ Faculty of Medicine and ${ }^{3}$ Liver Fluke and Cholangiocarcinoma Research Center, \\ KhonKaen University, KhonKaen 40002, Thailand
}

Received March 4, 2019; Accepted July 12, 2019

DOI: 10.3892/etm.2019.8041

\begin{abstract}
Pamidronate has been hypothesized to effectively inhibit cancer cell growth and metastasis in bone tissue. Furthermore, pamidronate (Pami) exerts various direct effects against several cancer cell types, including growth and migration. The present study aimed to determine the underlying mechanism of Pami's effect on the proliferation and migration of cholangiocarcinoma (CCA) cells. KKU-100 cells were used to determine the effects of Pami on cell death and migration. The following were assessed: Sulforhodamine B, colony formation, apoptosis via flow cytometry, reactive oxygen species (ROS) production and caspase-3 activity. In addition, the effects of the test compound on the mevalonate (MVA) signaling pathway were determined via western blotting and reverse transcription-quantitative PCR. Cell migration was observed via wound healing, Matrigel and gelatin zymography. The results indicated that Pami induced CCA cell death and inhibited colony formation in a dose-dependent manner, with $\mathrm{IC}_{50}$ values of $444.67 \pm 44.05 \mu \mathrm{M}$ at $24 \mathrm{~h}$ and $147.33 \pm 17.01 \mu \mathrm{M}$ at $48 \mathrm{~h}$. Furthermore, Pami treatment suppressed colony formation at a lower concentration than growth inhibition with $\mathrm{IC}_{50}$ values of $5.36 \pm 0.31 \mu \mathrm{M}$. The mechanism of growth inhibition was determined to potentially be associated with increased ROS generation and stimulated caspase-3 enzyme activity, leading to the induction of apoptosis. Furthermore, Pami treatment interfered with the MVA signaling pathway by reducing Racl protein levels and modulating the gene and protein expression of RhoA. Furthermore, Pami suppressed CCA cell migration by decreasing matrix metalloproteinase (MMP)2 and MMP9 levels. Additionally, Pami treatment
\end{abstract}

Correspondence to: Dr Benjaporn Buranrat, Faculty of Medicine, Mahasarakham University, 269 ME2 Building, Nakhornsawan Road, Muang, MahaSarakham 44000, Thailand

E-mail: buranrat@gmail.com

Key words: pamidronate, cholangiocarcinoma, Ras-related C3 botulinum toxin substrate 1 , matrix metalloproteinases, migration, apoptosis activated CCA cell death and inhibited CCA migration at low concentrations. Pami significantly decreased the protein expression levels of Racl in the MVA signaling pathway and may therefore be beneficial for developing a novel chemotherapeutic method for CCA.

\section{Introduction}

Pamidronate (Pami) is a type of bisphosphonate (BP) agent, which is a pyrophosphate analogue, and successfully used in the management of several bone diseases, including Paget's disease, osteoporosis and hypercalcemia-associated cancer cell damage. Additionally, BPs decrease bone pain or fractures in the elderly or patients with cancer with cancer cells migrating to the bone (1). In vitro studies show that BPs, including clodronate, alendronate, zoledronate and Pami (2-5), have an effect on cancer cells by suppressing the proliferation and induction of apoptosis. Interestingly, BPs inhibit bone metastasis and prolong the survival rate in patients with cancer. A study on patients with estrogen receptor (ER)-positive breast cancer indicated that zoledronic acid in combination with a hormone antagonist improves disease-free survival (6). Various studies suggest that BPs could be an anticancer agent for patients with prostate cancer $(7,8)$. Furthermore, BPs have beneficial effects on patients with prostate cancer who have cancer cells that migrate to the bones. Moreover, Pami inhibits PC-3 prostate cancer cells with high expression levels of Bcl-2 and anti-apoptotic protein (2). BPs have been demonstrated to have a high efficacy in cancer treatment in both in vitro and in vivo studies, and the deep effects of Pami on other cancer cells, including cholangiocarcinoma (CCA) cells, have been revealed.

The proposed mechanisms of BPs on cancer cells are indicated in several pathways and are important mechanisms in the inhibition of cell growth and migration (9-11). Furthermore, BPs decrease the gene-related cancer cell functions or replication $(12,13)$. Interestingly, one action of BPs is elucidated by the reduction of enzymes in the mevalonate (MVA) pathway, which reduces MVA products, such as farnesyl pyrophosphate (FPP) and geranylgeranyl pyrophosphate (GGPP) $(14,15)$ by suppressing the farnesyl pyrophosphate synthase (FPPS) enzyme. FPP and GGPP are crucial for producing intracellular 
proteins, including Rho, Ras, Rap and Rac, which are involved in the signaling pathways of normal and cancer functions (16). For tumor cells, MVA products can control cell differentiation, growth, migration, invasion and angiogenesis. Iguchi et al (2) have demonstrated that Pami inhibits prostate cancer cell proliferation through decreasing the MVA pathway and blocking Rap1, which is accompanied by the suppression of Bcl-2 expression. This is consistent with the results of Zhang et al (17), who demonstrated that Pami showed less activity against cancer cells, with low levels of MVA products, such as N-Ras or H-Ras. Therefore, the inhibition of the MVA pathway may be useful for inhibiting cancer cell growth and migration.

CCA, or bile duct cancer, is an aggressive cancer and a significant public health problem in Southeast Asian Countries, particularly in the North-Eastern part of Thailand. Infection by Opisthorchis viverrini (OV) is the main risk factor of CCA (17). OV infection can induce long-term chronic inflammation. The accumulation of numerous inflammatory cytokines and growth factors can lead to uncontrollable cancer cell growth and metastasis (18). CCA is frequently identified at an aggressive stage (stages III or IV) that is unsuitable for surgical treatment. Furthermore, standard chemotherapeutic drugs display low efficacy, high toxicity and high drug resistance (19). Therefore, novel anticancer agents, such as BPs, with high efficiency for CCA and low toxicity are urgently required.

In the present study, KKU-100 cells were used to examine the effects of Pami on CCA cell death, migration and the MVA pathway. To measure the cell death by sulforhodamine B (SRB), colony formation and apoptosis, reactive oxygen species (ROS) production, caspase-3 activity and flow cytometry assays were used. To test the effects of Pami on MVA products, RT-qPCR and western blotting were used. Finally, to assess the migration effects, wound healing, Matrigel and gelatin zymography assays were used.

\section{Materials and methods}

Cell cultures and cell death. Human CCA KKU-100 cells were provided by the Faculty of Medicine, Khon Kaen University. The cells were cultured in DMEM supplemented with penicillin $(100 \mathrm{U} / \mathrm{ml})$, streptomycin $(100 \mathrm{mg} / \mathrm{ml})$ and 10\% FBS. Cell death was examined by SRB assays as previously described (20). Cells were exposed to various concentrations of $0-1,000 \mu \mathrm{M}$ Pami or $0.25 \%$ dimethyl sulfoxide (DMSO) for 24 to $48 \mathrm{~h}$ and then fixed with $10 \%$ trichloroacetic acid (TCA), stained with $0.4 \%$ SRB and washed and solubilized in $10 \mathrm{mM}$ Tris base buffer. The optical density was measured at $540 \mathrm{~nm}$ and compared with the control groups.

Colony formation. KKU-100 cell colony formation was examined using a colony formation assay as previously described (20). Briefly, KKU-100 cells were exposed to various concentration of $0-100 \mu \mathrm{M}$ Pami or $0.25 \%$ DMSO for $24 \mathrm{~h}$. The DMEM medium was refreshed and cells were allowed to grow for 15 days. Next, the cells were washed with PBS buffer, fixed with absolute methanol, stained with $0.5 \%$ crystal violet, washed and dried. The colonies were counted and compared with the control groups.
Table I. Primer sequences for Rac1, RhoA and $\beta$-actin.

\begin{tabular}{ll}
\hline Gene & \multicolumn{1}{c}{ Primer sequences $\left(5^{\prime}-3^{\prime}\right)$} \\
\hline Rac1 & $\begin{array}{l}\text { Forward: ATGTCCGTGCAAAGTGGTATC } \\
\text { Reverse: CTCGGATCGCTTCGTCAAACA }\end{array}$ \\
RhoA & Forward: GGAAAGCAGGTAGAGTTGGCT \\
& Reverse: GGCTGTCGATGGAAAAACACAT \\
$\beta$-actin & Forward: GTGACGTTGACATCCGTAAAGA \\
& Reverse: GCCGGACTCATCGTACTCC \\
\hline
\end{tabular}

ROS generation. ROS production was assessed using a DHE-fluorescent probe, as previously described (20). KKU-100 cells were exposed to various concentrations of $0-250 \mu \mathrm{M}$ Pami or $0.25 \%$ DMSO with $25 \mu \mathrm{M}$ DHE-fluorescent probes in the dark for $90 \mathrm{~min}$. The fluorescent intensity for the excitation wavelength was read at $518 \mathrm{~nm}$ and for the emission wavelength at $605 \mathrm{~nm}$. The intensity was calculated and compared with the untreated groups.

Caspase-3 activity. Caspase-3 activity was examined with a caspase-3 assay kit, as previously described (20). Briefly, KKU-100 cells were exposed to various concentrations of $0-250 \mu \mathrm{M}$ Pami or $0.25 \%$ DMSO for $24 \mathrm{~h}$ and then caspase-3 activity was determined. The caspase- 3 activity was calculated from the fluorescent intensity and compared with the untreated groups.

Apoptosis. Apoptosis was tested by flow cytometry, as previously described with some modifications (21). Briefly, KKU-100 cells were exposed to various concentration of 0-250 $\mu \mathrm{M}$ Pami or $0.25 \%$ DMSO for $24 \mathrm{~h}$, stained with $5 \mu \mathrm{l}$ propidium iodide (PI) and $5 \mu \mathrm{l}$ Annexin V FITC and then incubated for $15 \mathrm{~min}$ in the dark. Apoptosis was measured by flow cytometry and compared with the control groups.

Wound healing. Migration was investigated using a wound healing assay, as previously described (20). KKU-100 cells were scratched with $0.2 \mathrm{ml}$ tips and incubated with various concentrations of $0-50 \mu \mathrm{M}$ Pami or $0.25 \%$ DMSO for $48 \mathrm{~h}$. Then, the cancer cells were fixed and stained with $0.5 \%$ crystal violet. The wound distance was calculated and compared with the control groups.

Matrigel migration. Migration was tested with a Matrigel migration assay, as previously described (22). KKU-100 cells were exposed to various concentrations of $0-100 \mu \mathrm{M}$ Pami or $0.25 \%$ DMSO for $24 \mathrm{~h}$ and, the next day, the inserted well was removed, washed and stained with $0.5 \%$ crystal violet. The migration of the cells was compared with the control groups.

Gelatin zymography. Migration was assessed by a gelatin zymography assay, as previously described (23). KKU-100 cells were exposed to various concentrations of 0-50 $\mu \mathrm{M}$ Pami or $0.25 \%$ DMSO for $24 \mathrm{~h}$, the medium was collected and the protein concentration was measured. The protein was loaded onto $10 \%$ SDS-PAGE gels with $0.01 \%$ gelatin $(\mathrm{w} / \mathrm{v})$. The gels 
A

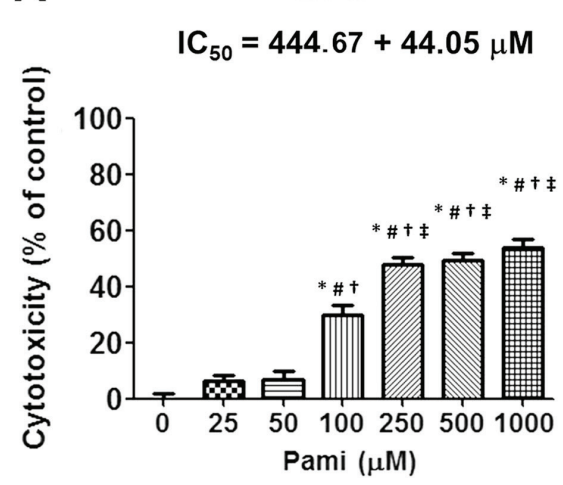

C

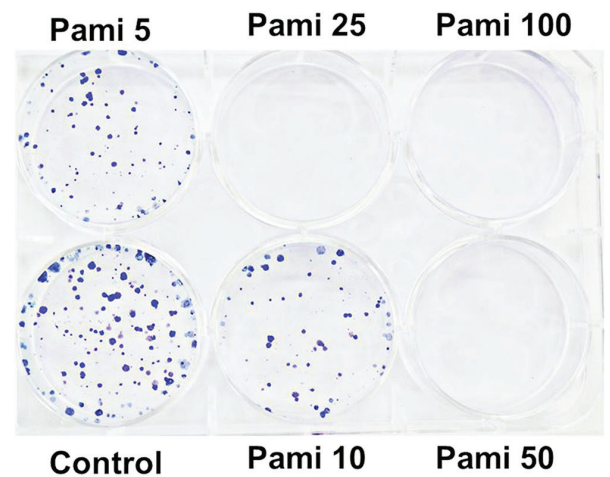

B $\quad 48 \mathrm{~h}$

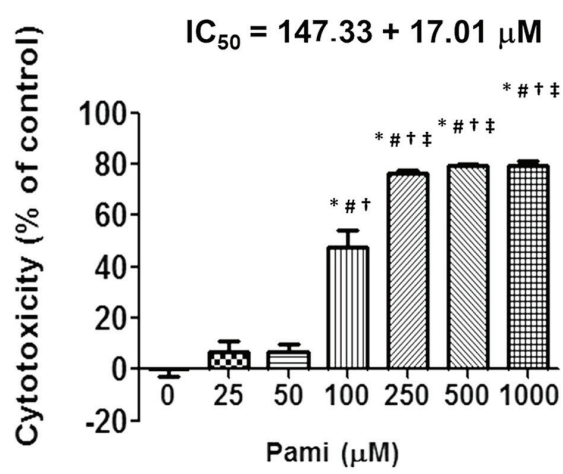

D

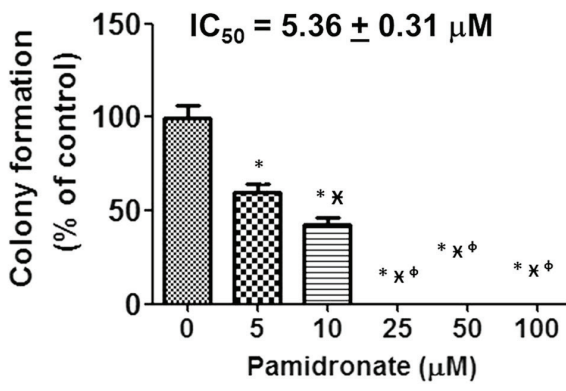

Figure 1. Effect of Pami on CCA cell growth. KKU-100 cells were incubated with Pami and cytotoxicity was assessed for (A) 24 and (B) 48 h. Sulforhodamine B and colony formation assays were also performed and presented as (C) representative images and (D) a bar graph. Data are presented as the mean \pm standard error. ${ }^{*} \mathrm{P}<0.05$ vs. $0 \mu \mathrm{M} ;{ }^{\circledR} \mathrm{P}<0.05$ vs. $5 \mu \mathrm{M} ;{ }^{\star} \mathrm{P}<0.05$ vs. $10 \mu \mathrm{M} ;{ }^{*} \mathrm{P}<0.05$ vs. $25 \mu \mathrm{M}$; ${ }^{\dagger} \mathrm{P}<0.05$ vs. $50 \mu \mathrm{M}$; ${ }^{\dagger} \mathrm{P}<0.05$ vs. $100 \mu \mathrm{M}$. CCA, cholangiocarcinoma; Pami, pamidronate.

were incubated with developing buffer overnight and stained with $0.5 \%$ Coomassie brilliant blue R-250 until a clear band was observed. The band density was calculated and compared with that of the control groups.

Reverse transcription-quantitative $(R T-q) P C R$. Gene expression levels were assessed by RT-qPCR, as previously described $(23,24)$. Briefly, KKU-100 cells were exposed to $250 \mu \mathrm{M}$ Pami or $0.25 \%$ DMSO for $24 \mathrm{~h}$. Afterwards, cellular RNA was extracted and transcribed intro complementary DNA using the iScript ${ }^{\mathrm{TM}}$ cDNA Synthesis kit (cat. no. 1708898; Bio-Rad Laboratories, Inc.) at $42^{\circ} \mathrm{C}$ for $60 \mathrm{~min}$. Racl and RhoA gene expression were examined by RT-qPCR and primers for the target genes are shown in Table I. A final reaction volume of $20 \mu 1$ was prepared containing SsoFast ${ }^{\mathrm{TM}}$ EvaGreen Supermix with low Rox (Bio-Rad Laboratories, Inc.), and primers for the target gene and the internal control $\beta$-actin. The PCR conditions were as follows: Denaturation at $95^{\circ} \mathrm{C}$ for $3 \mathrm{~min}$ and amplification by cycling 40 times at $95^{\circ} \mathrm{C}$ for $15 \mathrm{sec}$ and $60^{\circ} \mathrm{C}$ for $30 \mathrm{sec}$. Expression was detected using a CFX96 Touch $^{\mathrm{TM}}$ real-time PCR Detection system (Bio-Rad Laboratories, Inc.). Differences in gene expression levels were calculated using the $2^{-\Delta \Delta \mathrm{Cq}}$ method (24) for relative quantification and expressed as the fold change relative to the untreated control. Assays assessing target gene expression were performed in triplicate.

Western blotting. Protein expression levels were assessed by western blotting, as previously described (23). Briefly, KKU-100 cells were exposed to $250 \mu \mathrm{M}$ Pami or $0.25 \%$ DMSO for $24 \mathrm{~h}$, the cell pellet was collected, the cells were lysed and the protein concentration was measured. The protein was loaded onto a $12 \%$ SDS-PAGE gel, which was blocked and incubated with primary antibodies against Rac1 (1:1,000 dilution), RhoA (1:1,000 dilution) and beta-actin (1:2,500 dilution). Membranes were exposed to the secondary antibody (1:2,500 dilution) the following day. The ECL substrate was used to detect the band intensity and this was compared with the control groups.

Statistical analysis. Data from three independent experiments were statistically compared using Student's t-test and one-way ANOVA followed by Tukey's post hoc test. The significance was set at 0.05 compared with the control by using SigmaStat software version 3.5 (Systat Software Inc.), and the $\mathrm{IC}_{50}$ values calculations and statistical analyses were performed using Prism 5 software (GraphPad Software, Inc.).

\section{Results}

Pami induces cell death and inhibits colony formation. The results from the SRB assay indicated that Pami suppressed CCA cells at 24 and 48 h (Fig. 1A and B). Notably, at doses between 100 and 1,000 $\mu \mathrm{M}$ Pami exhibited significant effects compared with the control groups. Compared with the incubation time point, a significant difference was identified in $\mathrm{IC}_{50}$ values of $444.67 \pm 44.05 \mu \mathrm{M}$ for $24 \mathrm{~h}$ and $\mathrm{IC}_{50}$ values of $147.33 \pm 17.01 \mu \mathrm{M}$ for $48 \mathrm{~h}$ for Pami effects. Accordingly, 

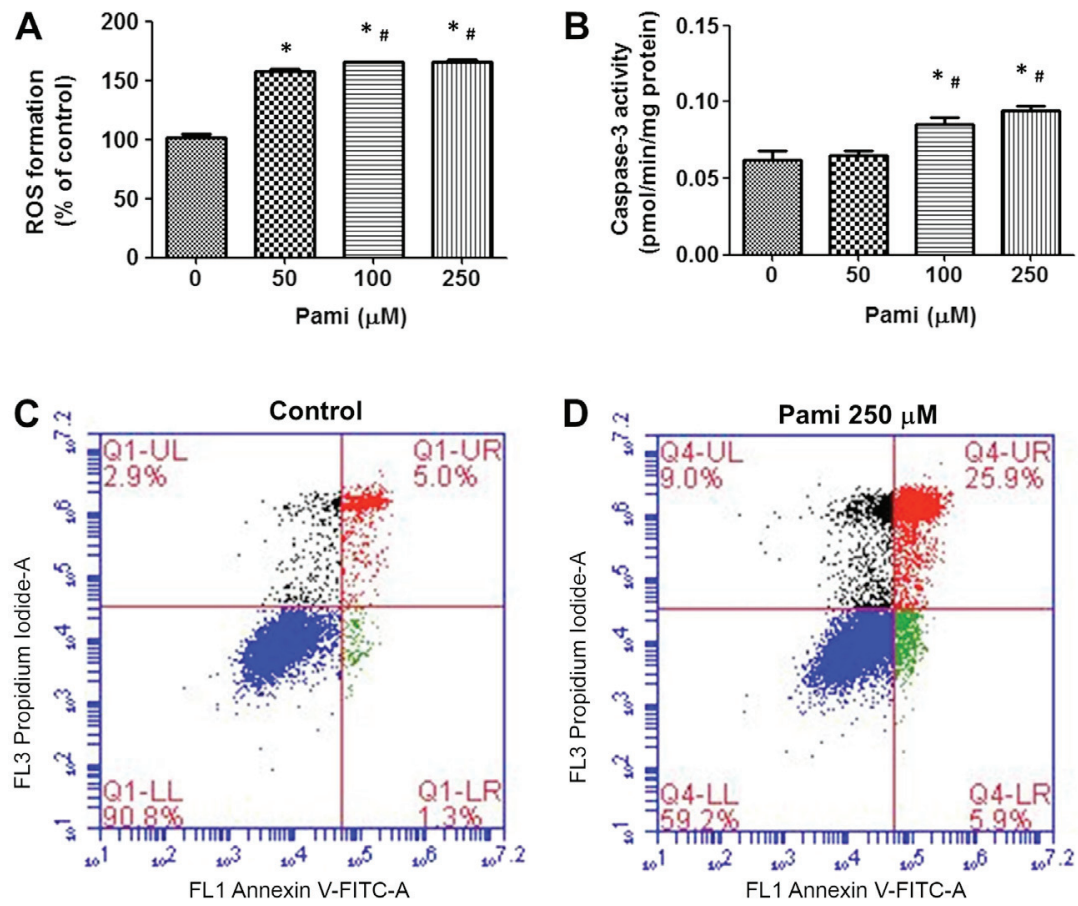

Figure 2. Effect of Pami on ROS production, caspase-3 levels and apoptosis. KKU-100 cells were incubated with Pami and evaluated for ROS production, caspase-3 levels and apoptosis with a (A) DHE-fluorescent probe, (B) caspase-3 assay kit and flow cytometry for (C) control and (D) treatment groups. Data are presented as the mean \pm standard error. ${ }^{*} \mathrm{P}<0.05$ vs. $0 \mu \mathrm{M}$; ${ }^{*} \mathrm{P}<0.05$ vs. $50 \mu \mathrm{M}$. Pami, pamidronate; ROS, reactive oxygen species.

A

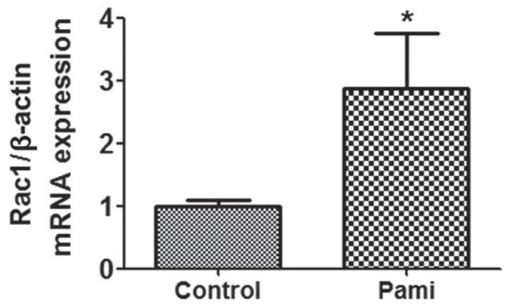

B

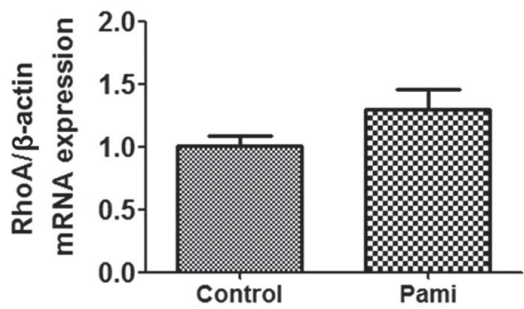

C

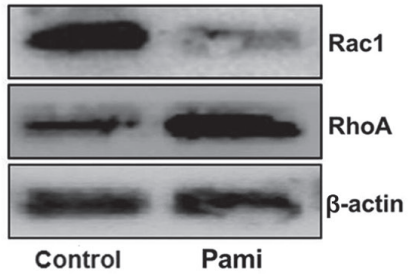

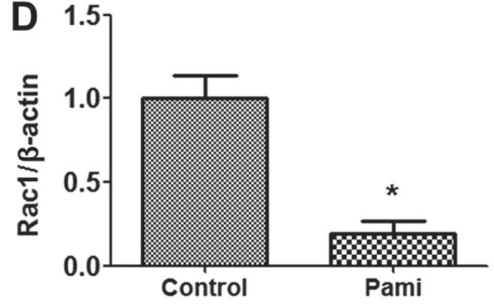

E

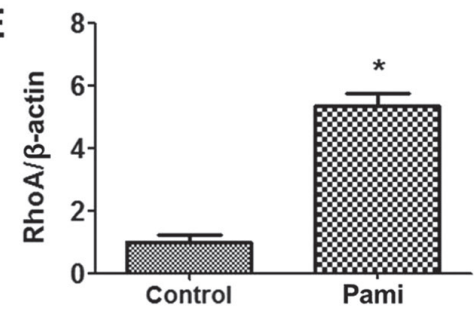

Figure 3. Effect of Pami on Rac1 and RhoA gene and protein expression. Following incubation with $250 \mu \mathrm{M}$ Pami, reverse transcription-quantitative PCR was performed to detect the gene and protein expression of (A) Rac1 and (B) RhoA in KKU-100 cells. (C) Western blotting was performed and the expression of (D) Rac1 and (E) RhoA was semi-quantified. Data are presented as the mean \pm standard error. ${ }^{*} \mathrm{P}<0.05$ vs. control. Pami, pamidronate.

for growth inhibition, colony formation was repressed in a concentration-dependent manner with the lower concentration at $\mathrm{IC}_{50}$ values of $5.36 \pm 0.31 \mu \mathrm{M}$ when compared with the growth inhibition (Fig. 1C and D).

Pami induces cell apoptosis. The data indicated that Pami stimulated intracellular ROS generation after incubation for 90 min (Fig. 2A) when compared with control group. Correlating with the caspase-3 activity, Pami induced caspase- 3 activity in a dose-dependent way at $24 \mathrm{~h}$ and showed significant levels between the control groups at 100-250 $\mu \mathrm{M}$
(Fig. 2B). Testing cancer cell apoptosis by flow cytometry, Pami caused significant induction of CCA apoptosis and necrosis (Fig. 2C and D).

Pami decreases MVA product expression levels. When exploring the Rac1 and RhoA gene expression with RT-qPCR, after CCA cells were exposed to Pami, the Pami effects modulated the Racl gene expression more than the RhoA gene expression, and the Racl gene expression was induced following incubation with Pami for $24 \mathrm{~h}$, whereas RhoA gene expression was not altered (Fig. 3A and B). When 
A
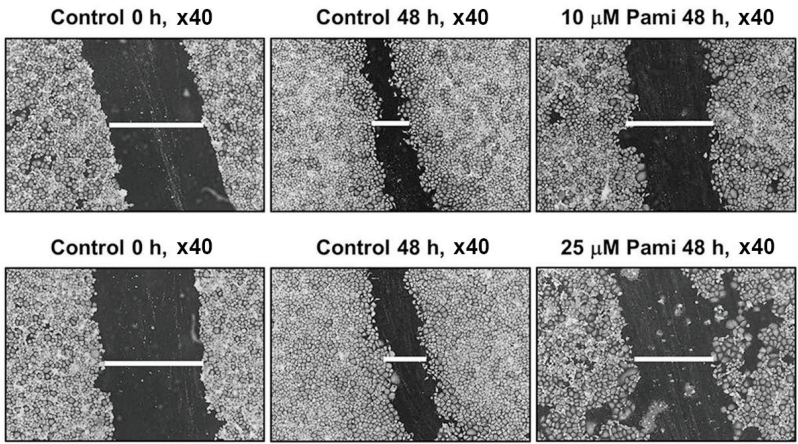

Control $0 \mathrm{~h}, \mathrm{x} 40$

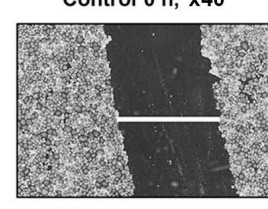

Control $48 \mathrm{~h}, \mathbf{x} 40$

$25 \mu \mathrm{M}$ Pami 48 h, $x 40$

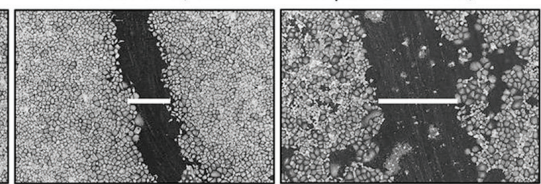

Control 48 h, x40

$50 \mu \mathrm{M}$ Pami 48 h, x40

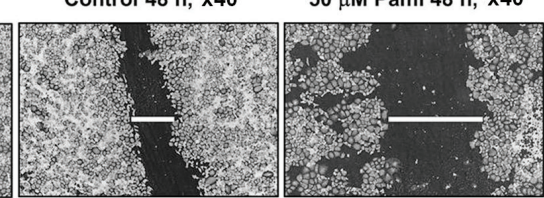

B
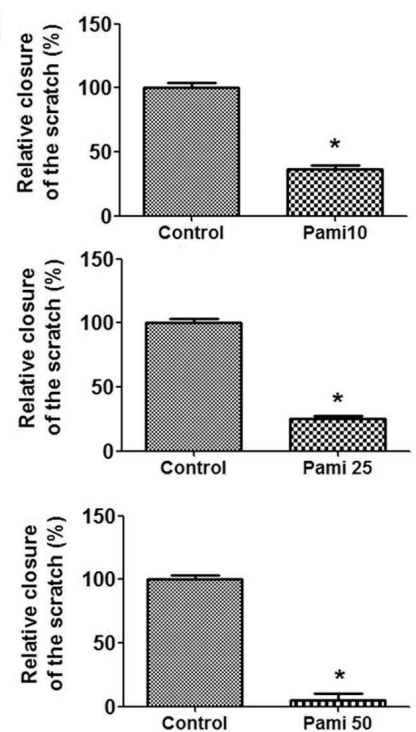

C

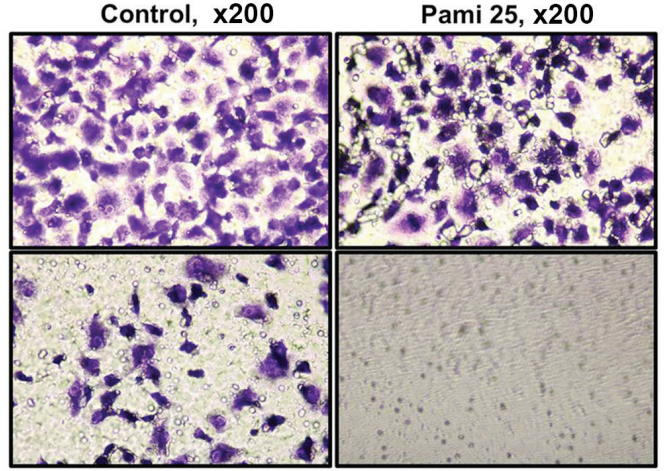

Pami 50, x200

Pami 100, x200
D

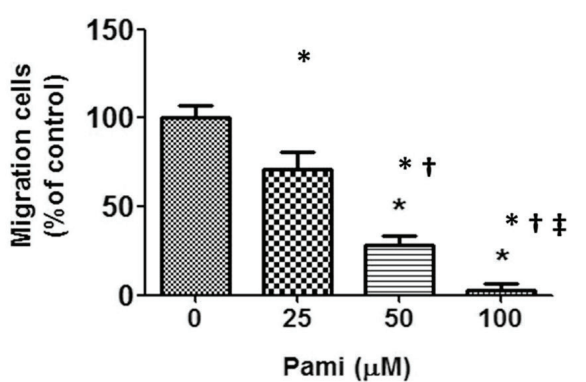

E

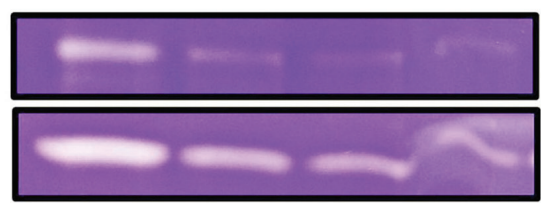

MMP 2

MMP 9

Control Pami 10 Pami 25 Pami 50

$\mathbf{F}$

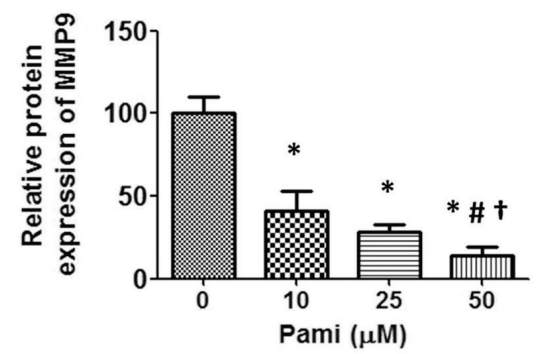

G

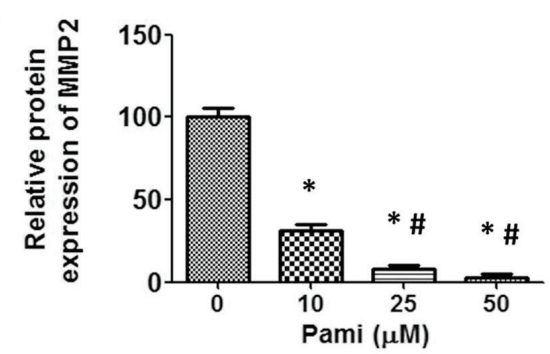

Figure 4. Effect of Pami on CCA cell migration. Following incubation with Pami, a wound healing assay was performed using KKU-100 cells. (A) Distance of wound healing, (B) relative closure of the scratch, (C) cell migration to the bottom chamber and (D) migrated cells are presented. (E) Gel zymography and the expression of (F) MMP9 and (G) MMP2 were also assessed. Data are presented as mean the \pm standard error. ${ }^{*} \mathrm{P}<0.05$ vs. control; ${ }^{*} \mathrm{P}<0.05 \mathrm{vs}$. $10 \mu \mathrm{M}$; ${ }^{\dagger} \mathrm{P}<0.05$ vs. $25 \mu \mathrm{M}$; ${ }^{\stackrel{P}{ }<}<0.05$ vs. $50 \mu \mathrm{M}$. CCA, cholangiocarcinoma; Pami, pamidronate.

determining the protein expression by western blotting, the Rac1 protein levels were decreased at $24 \mathrm{~h}$ incubation, but RhoA protein levels were increased (Fig. 3C-E).

Pami reduces migration. The results showed that Pami blocked wound healing effects after cells were scratched with a $0.2 \mathrm{ml}$ pipette tip (Fig. $4 \mathrm{~A}$ and B) and then lead to the inhibition of CCA cell migration (Fig. $4 \mathrm{C}$ and D) to the bottom of the Transwell chamber. Next, to explore the mechanism associated with the blocking of the CCA migration, a gelatin zymography assay was used. The results showed that Pami strongly decreased both MMP2 and MMP9 expression 
levels, which were secreted in the culture media, especially the MMP9 levels (Fig. 4E-G).

\section{Discussion}

The present study demonstrated that BPs can directly suppress cancer cell growth, induce apoptosis and inhibit cell migration, which was associated with the MVA pathway in CCA cell lines. The MVA pathway serves a crucial role in the cancer process and the biology that controls the intracellular pathway in tumors, such as cell proliferation, growth, invasion and migration, as well as resistance to chemotherapeutic agents. Therefore, the MVA pathway is of interest if it can be inhibited or reduced by drugs or natural products. The present study reported that Pami inhibited CCA cell growth in SRB and colony formation assays, which was accompanied by induction of CCA cell apoptosis as examined by ROS generation, caspase- 3 activity and apoptosis by flow cytometry. Furthermore, Pami was revealed to modulate the MVA pathway and suppress Racl protein expression levels $24 \mathrm{~h}$ after incubation. Finally, Pami also decreased the CCA cell migration by inhibiting wound healing and the invasion in the Matrigel assay, as well as reducing MMP2 and MMP9 levels. The data demonstrated that Pami acted against CCA cells with effects on growth inhibition, apoptotic induction and migratory suppression. Pami may be useful against CCA cells.

Pami suppressed the MVA pathway and downregulated the downstream protein targets of MVA products, including Rac and Rho, which control cell growth, proliferation and migration (17). According to the results of the present study, Pami modulated Racl and RhoA gene and protein expression levels. Especially, Pami suppressed Rac1 protein expression, which may have upregulated Racl gene expression at $24 \mathrm{~h}$. Racl and RhoA are Rho GTPase family members that regulate actin dynamics and cell proliferation (24). Rac1 regulates multiple signaling pathways that control cytoskeleton organization, transcription and cell growth (25). Direct inhibition of Rac1 activity induces cell cycle arrest and apoptosis in human breast cancer cells (26), as well as CCA (27). Miller et al (27) found that simvastatin is a HMG-CoA reductase enzyme inhibitor that is important for inhibition of the MVA pathway, it decreases Rac1 activity in CCA cells (Mz-ChA-1 cells) and causes induction of CCA cell death by increasing levels of cleaved caspase-3 and reducing p-ERK levels (28). Similar to these results, Pami suppressed Rac1 protein expression and further induced CCA cell death and apoptosis by activating ROS formation and inducing caspase-3 activity. However, our previous study showed that Pami suppresses Racl and RhoA gene expression in MCF-7 breast cancer cells following incubation for $24 \mathrm{~h}$ (data not shown). Therefore, the bisphosphonate on the MVA products both in gene and protein expression are required to explore the time and concentration for each cancer cell type in further experiments. Data indicated that the inhibition of the MVA pathway was associated with CCA cell death and apoptosis. Further experiments are required to explore the dose and incubation time associated with Rac1 and RhoA levels.

Regarding CCA cell apoptosis, at a dose of $250 \mu \mathrm{M}$, Pami caused a significant induction of apoptosis through ROS formation and caspase- 3 activity. The data revealed that Pami in the dose range 50-250 $\mu \mathrm{M}$ induced ROS formation and also significantly stimulated caspase-3 activity at doses of 100-250 $\mu \mathrm{M}$. In the present study, only $250 \mu \mathrm{M}$ Pami was used to study apoptosis by flow cytometry as it showed higher effects in terms of activating CCA cell apoptosis. Riebeling et al (29) reported that $100 \mu \mathrm{M}$ Pami stimulates melanoma cell apoptosis through caspase-3 overexpression and DNA fragmentation. Additionally, low doses of Pami (1-20 $\mu \mathrm{M})$ reduce MVA products, including Ras, RhoA and ROCK-1, and are associated with the induction of cleaved caspase- 3 and -9 , and the reduction of antiapoptotic protein Bcl-2 (30). Pami exhibited high efficacy in accelerating CCA cell apoptosis.

Regarding CCA cell metastasis, it was revealed that Pami inhibited CCA cell migration in a dose-dependent manner by reducing MMP2 and MMP expression levels. Metastasis is the important step where tumor cells migrate from the original site to a distant site and contribute to secondary tumors. Lai et al (31) demonstrated that alendronate may decrease MMP2 gene and protein expression and further correlated with inhibiting the invasion of chondrosarcoma cells. Furthermore, four types of BPs, such as zoledronate, clodronate, Pami and alendronate, at non-cytotoxic doses suppressed MMP1, -2, $-3,-8,-9,-12,-13$ and -20 (32) as in these migration results. Interestingly, $10 \mu \mathrm{M}$ Pami decreased the invasion, migration and RhoA gene and protein expression in breast cancer cells by downregulating the Serpin-Al gene (33). Similarly, Wada et al (30) indicated that Pami can suppress membrane RhoA and lead to inhibited hepatocellular carcinoma (HCC) motility. Moreover, Pami potentiated the effects of statins on the reduction of tumor cell adhesion to collagen IV and fibronectin and suppression of the migration and invasiveness of tumor cells (34). BPs can be applied for antiinvasive and anti-metastatic activities, which may inhibit cancer metastasis including CCA.

The current in vitro study presents a first report of Pami efficacy on CCA cells by inhibiting growth, inducing apoptosis and suppressing migration. Further in vivo studies are essential to examine these effects and establish the safety and efficacy of the Pami studied in this model before treating patients with CCA.

\section{Acknowledgements}

Not applicable.

\section{Funding}

The present study was financially supported by the Thailand Research Fund (grant no. MRG6080071).

\section{Availability of data and materials}

The datasets used and/or analyzed during the current study are available from the corresponding author on reasonable request.

\section{Authors' contributions}

$\mathrm{BB}, \mathrm{LS}$ and AP performed the experiments and analyzed the data. BB and VK guided the experiments, designed the study and wrote the manuscript. All authors gave final approval of the version to be published. All authors read and approved the 
manuscript and agree to be accountable for all aspects of the research in ensuring that the accuracy or integrity of any part of the work are appropriately investigated and resolved.

\section{Ethics approval and consent to participate}

Not applicable.

\section{Patient consent for publication}

Not applicable.

\section{Competing interests}

The authors declare that they have no competing interests.

\section{References}

1. Fleisch H: Development of bisphosphonates. Breast Cancer Res 4: 30-34, 2002.

2. Iguchi K, Tatsuda Y, Usui S and Hirano K: Pamidronate inhibits antiapoptotic bcl-2 expression through inhibition of the mevalonate pathway in prostate cancer PC-3 cells. Eur J Pharmacol 641: 35-40, 2010.

3. Iguchi T, Miyakawa Y, Saito K, Nakabayashi C, Nakanishi M, Saya H, Ikeda Y and Kizaki M: Zoledronate-induced S phase arrest and apoptosis accompanied by DNA damage and activation of the ATM/Chk1/cdc25 pathway in human osteosarcoma cells. Int J Oncol 31: 285-291, 2007.

4. Molinuevo MS, Bruzzone L and Cortizo AM: Alendronate induces anti-migratory effects and inhibition of neutral phosphatases in UMR 106 osteosarcoma cells. Eur J Pharmacol 562: 28-33, 2007.

5. Zeisberger SM, Odermatt B, Marty C, Zehnder-Fjällman AH, Ballmer-Hofer K and Schwendener RA: Clodronateliposome-mediated depletion of tumour-associated macrophages: A new and highly effective antiangiogenic therapy approach. Br J Cancer 95: 272-281, 2006.

6. Gnant M, Mlineritsch B, Schippinger W, Luschin-Ebengreuth G, Pöstlberger S, Menzel C, Jakesz R, Seifert M, Hubalek M, Bjelic-Radisic V, et al: Endocrine therapy plus zoledronic acid in premenopausal breast cancer. N Engl J Med 360: 679-691, 2009.

7. Asahi H, Mizokami A, Maeda Y, Komatsu K, Koshida K and Namiki M: Bisphosphonate therapy for hormone refractory prostate cancer with bone metastasis. J Urol 169: 281-282, 2003.

8. Smith MR, McGovern FJ, Zietman AL, Fallon MA, Hayden DL, Schoenfeld DA, Kantoff PW and Finkelstein JS: Pamidronate to prevent bone loss during androgen-deprivation therapy for prostate cancer. N Engl J Med 345: 948-955, 2001

9. Boissier S, Ferreras M, Peyruchaud O, Magnetto S, Ebetino FH, Colombel M, Delmas P, Delaissé JM and Clézardin P: Bisphosphonates inhibit breast and prostate carcinoma cell invasion, an early event in the formation of bone metastases. Cancer Res 60: 2949-2954, 2000.

10. Iguchi K, Matsunaga S, Nakano T, Usui S and Hirano K Inhibition of caveolin-1 expression by incadronate in PC-3 prostate cells. Anticancer Res 26: 2977-2981, 2006.

11. Nishida S, Fujii Y, Yoshioka S, Kikuichi S, Tsubaki M and Irimajiri K: A new bisphosphonate, YM529 induces apoptosis in HL60 cells by decreasing phosphorylation of single survival signal ERK. Life Sci 73: 2655-2664, 2003.

12. Asahi H, Mizokami A, Miwa S, Keller ET, Koshida K and Namiki M: Bisphosphonate induces apoptosis and inhibits pro-osteoclastic gene expression in prostate cancer cells. Int J Urol 13: 593-600, 2006.

13. Valenti MT, Bertoldo F, Dalle Carbonare L, Azzarello G, Zenari S, Zanatta M, Balducci E, Vinante $\mathrm{O}$ and Lo Cascio V: The effect of bisphosphonates on gene expression: GAPDH as a housekeeping or a new target gene? BMC Cancer 6: 49, 2006.

14. Oades GM, Senaratne SG, Clarke IA, Kirby RS and Colston KW: Nitrogen containing bisphosphonates induce apoptosis and inhibit the mevalonate pathway, impairing Ras membrane localization in prostate cancer cells. J Urol 170: 246-252, 2003.
15. Virtanen SS, Väänänen HK, Härkönen PL and Lakkakorpi PT: Alendronate inhibits invasion of PC-3 prostate cancer cells by affecting the mevalonate pathway. Cancer Res 62: 2708-2714, 2002

16. Walker K and Olson MF: Targeting Ras and Rho GTPases as opportunities for cancer therapeutics. Curr Opin Genet Dev 15: 62-68, 2005

17. Zhang PL, Lun M, Siegelmann-Danieli N, Blasick TM and Brown RE: Pamidronate resistance and associated low ras levels in breast cancer cells: A role for combinatorial therapy. Ann Clin Lab Sci 34: 263-270, 2004.

18. Sripa B, Brindley PJ, Mulvenna J, Laha T, Smout MJ, Mairiang E, Bethony JM and Loukas A: The tumorigenic liver fluke Opisthorchis viverrini-multiple pathways to cancer. Trends Parasitol 28: 395-407, 2012.

19. Sookprasert A, Chindaprasert J and Wirasorn K: Systemic therapy for locally advanced and metastatic cholangiocarcinoma. Asian Pac J Cancer Prev (Suppl 13): 3-6, 2012.

20. Buranrat B, Mairuae N and Kanchanarach W: Cytotoxic and antimigratory effects of Cratoxy formosum extract against HepG2 liver cancer cells. Biomed Rep 6: 441-448, 2017.

21. Klungsaeng S, Kukongviriyapan V, Prawan A, Kongpetch S and Senggunprai L: Cucurbitacin B induces mitochondrial-mediated apoptosis pathway in cholangiocarcinoma cells via suppressing focal adhesion kinase signaling. Naunyn Schmiedebergs Arch Pharmacol 392: 271-278, 2019.

22. Chen H, Wang C, Qi M, Ge L, Tian Z, Li J, Zhang M, Wang M, Huang L and Tang X: Anti-tumor effect of Rhaponticum uniflorum ethyl acetate extract by regulation of peroxiredoxin1 and epithelial-to-mesenchymal transition in oral cancer. Front Pharmacol 8: 870, 2017

23. Buranrat B, Mairuae N and Konsue A: Cratoxy formosum leaf extract inhibits proliferation and migration of human breast cancer MCF-7 cells. Biomed Pharmacother 90: 77-84, 2017.

24. Livak KJ and Schmittgen TD: Analysis of relative gene expression data using real-time quantitative PCR and the 2(-Delta Delta C(T)) method. Methods 25: 402-408, 2001.

25. Bosco EE, Mulloy JC and Zheng Y: Racl GTPase: A 'Rac' of all trades. Cell Mol Life Sci 66: 370-374, 2009.

26. Yoshida T, Zhang Y, Rivera Rosado LA, Chen J, Khan T, Moon SY and Zhang B: Blockade of Racl activity induces G1 cell cycle arrest or apoptosis in breast cancer cells through downregulation of cyclin D1, survivin, and X-linked inhibitor of apoptosis protein. Mol Cancer Ther 9: 1657-1668, 2010.

27. Miller T, Yang F, Wise CE, Meng F, Priester S, Munshi MK, Guerrier M, Dostal DE and Glaser SS: Simvastatin stimulates apoptosis in cholangiocarcinoma by inhibition of Racl activity. Dig Liver Dis 43: 395-403, 2011.

28. Kamigaki M, Sasaki T, Serikawa M, Inoue M, Kobayashi K, Itsuki H, Minami T, Yukutake M, Okazaki A, Ishigaki T, et al: Statins induce apoptosis and inhibit proliferation in cholangiocarcinoma cells. Int J Oncol 39: 561-568, 2011.

29. Riebeling C, Forsea AM, Raisova M, Orfanos CE and Geilen CC: The bisphosphonate pamidronate induces apoptosis in human melanoma cells in vitro. Br J Cancer 87: 366-371, 2002.

30. Wada A, Fukui K, Sawai Y, Imanaka K, Kiso S, Tamura S, Shimomura I and Hayashi N: Pamidronate induced anti-proliferative, apoptotic, and anti-migratory effects in hepatocellular carcinoma. J Hepatol 44: 142-150, 2006.

31. Lai TJ, Hsu SF, Li TM, Hsu HC, Lin JG, Hsu CJ, Chou MC, Lee MC, Yang SF and Fong YC: Alendronate inhibits cell invasion and MMP-2 secretion in human chondrosarcoma cell line. Acta Pharmacol Sin 28: 1231-1235, 2007.

32. HeikkiläP,Teronen O, Moilanen M,Konttinen YT,HanemaaijerR, Laitinen M, Maisi P, van der Pluijm G, Bartlett JD, Salo T and Sorsa T: Bisphosphonates inhibit stromelysin-1 (MMP-3), matrix metalloelastase (MMP-12), collagenase-3 (MMP-13) and enamelysin (MMP-20), but not urokinase-type plasminogen activator, and diminish invasion and migration of human malignant and endothelial cell lines. Anticancer Drugs 13: 245-254, 2002.

33. Ponce-Cusi R and Calaf GM: Antitumor activity of pamidronate in breast cancer cells transformed by low doses of $\alpha$-particles and estrogen in vitro. Int J Oncol 46: 2663-2669, 2015.

34. Issat T, Nowis D, Legat M, Makowski M, Klejman MP, Urbanski J, Skierski J, Koronkiewicz M, Stoklosa T, Brzezinska A, et al: Potentiated antitumor effects of the combination treatment with statins and pamidronate in vitro and in vivo. Int $\mathrm{J}$ Oncol 30: $1413-1425,2007$

This work is licensed under a Creative Commons Attribution-NonCommercial-NoDerivatives 4.0 International (CC BY-NC-ND 4.0) License. 